\title{
Universal immuno-PCR for ultra-sensitive target protein detection
}

\author{
Hong Zhou ${ }^{\star}$, Robert J.Fisher and Taki S.Papas ${ }^{1,+}$ \\ Laboratory of Cellular Biochemistry, PRI/DynCorp, Frederick, MD 21702, USA and 'Laboratory of \\ Molecular Oncology, National Cancer Institute, National Institutes of Health, Frederick, MD 21702, \\ USA
}

Received November 3, 1993; Revised and Accepted November 19, 1993

The exponential amplification power of polymerase chain reaction (1) for immunoassays applying antibodies has been recently explored by Sano, et al. so that as few as several hundreds of molecules of antigen in small volumes of aqueous sample could be detected (2). However, the limited availability of its key component, a streptavidin-protein $\mathrm{A}$ fusion protein, and the widely varied affinities of protein A with antibodies of various classes and subclasses from different species (3) limited its immediate applications. We have substituted the fusion protein with commercially available biotinylated secondary antibodies and free streptavidin, modified the sample dilution solution and reduced washing steps to a reasonable scale. The resulting procedure retains the sensitivity and specificity of the original Immuno-PCR, but can be universally applied without any Ig source or (sub)class restrictions.

A full-length recombinant human proto-oncogene ETS1 (4), purified from bacteria inclusion bodies, was used as the target antigen. One of the critical improvements in these assays was the use of a modified antigen dilution buffer (MADB). In initial trials using TBS (150 mM NaCl and $20 \mathrm{mM}$ Tris $-\mathrm{Cl}, \mathrm{pH} 7.4$ ) for antigen dilution, both regular ELISA and Immuno-PCR could only yield signals in the very first three tenfold dilutions. By adjusting the guanidine concentration in TBS to $2 \mathrm{M}$, we solved the antigen solubility problem. The second improvement was a reduction of washing scale. In the original Immuno-PCR protocol (2), exhaustive washing was carried out to eliminate possible carry-over contamination and non-specific binding. This demanded a great amount of hands-on time. By estimation, we found that, with a $250 \mu \mathrm{l}$-wash volume, a 3 time-washing schedule is sufficient to dilute any carry-over contamination left by up to $1 \mu \mathrm{l}$ of primary antibody at $0.1 \mathrm{ng} / \mu \mathrm{l}$ concentration, which is $2 \%$ of reagent volume, down to $6.4 \times 10^{-9} \mathrm{ng}$, i.e. $\sim 4 \times 10^{-23}$ $\mathrm{M}$ or $\sim 24$ molecules. Therefore, the washing step was reduced from 7-15 times in the original protocol to 3-5 times.

We then started by preparing a serial tenfold dilutions of the ETS1 stock with MADB. $100 \mu$ l solutions at concentrations from $1.92 \times 10^{-11} \mathrm{~mol} / \mu \mathrm{l}$ to $1.92 \times 10^{-23} \mathrm{~mol} / \mu \mathrm{l}$ were made in Immulon-4 strips mounted in a frame (Dynatech). $50 \mu \mathrm{l}$ of the dilutions at each concentration was then transferred to corresponding ultra thin-wall PCR tubes (PGC). Both the strips and the tubes were incubated overnight at $4^{\circ} \mathrm{C}$ to immobilize the antigen.

The ETS1-coated strips were used for ELISA which served as a comparison with the Immuno-PCR. The antigen solutions was decanted using an 8-position straight manifold (Wheaton) and a decanting bottle connected to house-vacuum. The wells were then washed three times with $250 \mu \mathrm{l}$ TBS and blocked with $200 \mu \mathrm{l}$ MESTBS (TBS supplemented with $4.5 \%$ nonfat dried milk, $0.1 \mathrm{mM}$ EDTA, $1 \mathrm{mg} / \mathrm{ml}$ salmon sperm DNA and $0.2 \%$ sodium azide) at $37^{\circ} \mathrm{C}$ for 1 hour. Successive washing steps after each incubation step were all composed of three times of threeminute, $250 \mu$ l TETBS (TBS supplemented with $0.04 \%$ Tween and $0.1 \mathrm{mM}$ EDTA). Purified ETS1-specific mAb E44, biotinylated sheep anti-mouse secondary antibody and streptavidin-alkaline phosphatase conjugate (both from Amersham's Western Immunodetection kit) were all diluted with a reagent dilution buffer (RDB) composed of 1 part of MESTBS plus nine parts of TETBS. The incubation time was kept identical for one hour at room temperature $\left(\sim 22^{\circ} \mathrm{C}\right)$. After incubation with AP-streptavidin conjugate and subsequent washing, $50 \mu \mathrm{l}$ $1 \mathrm{mg} / \mathrm{ml} \mathrm{p}$-Nitrophenyl phosphate disodium substrate (prepared using Sigma's pNPP capsules) in $0.1 \mathrm{M}$ Tris $-\mathrm{Cl}, \mathrm{pH}$ 9.4, containing $50 \mathrm{mM} \mathrm{MgCl} 2$ (6) was added to each well and allowed to develop for about 10 minutes before the reaction was stopped with $50 \mu \mathrm{l} 0.1 \mathrm{M}$ EDTA. The yielded signals were then measured at $405 \mathrm{~nm}$ using an ELISA plate reader. With this routine ELISA assay, a linear $\mathrm{OD}_{405}$-ETS1 mass relationship could be seen in the range of concentrations from $0.1 \mathrm{ng} / \mu \mathrm{l}$ to $1 \mu \mathrm{g} / \mu \mathrm{l}$ and ETS 1 at concentrations as low as $10 \mathrm{pg} / \mu \mathrm{l}$ still could be detected without losing specificity (Figure 1).

The coated tubes were used to evaluate the universal ImmunoPCR procedure. Procedures up to the biotinylated secondary antibody addition were identical to those in the control ELISA. Afterwards, $50 \mu \mathrm{l}$ free streptavidin (Pierce) at $1 \mathrm{ng} / \mu \mathrm{l}$ was added to each tube and incubated at room temperature for one hour. The DNA tag was prepared by digesting $2 \mu \mathrm{g}$ p $\alpha$ TEL $14^{7}$ with $10 \mathrm{U}$ EcoRI (New England Biolabs) in $20 \mu \mathrm{l}$ reaction, followed by biotinylation with $2.5 \mathrm{U}$ Klenow fragment (New England Biolabs) and $20 \mu \mathrm{M}$ Biotin-14-dATP (BRL) and agarose gel purification. After incubation with free streptavidin and \footnotetext{
${ }^{+}$To whom correspondence should be addressed at: Department of Cancer Biology, School of Public Health, Harvard University, Bldg 1, Room 708,
665 Huntingdon Avenue, Boston, MA 02115, USA *Present address: Center for Molecular and Structural Biology, Hollings Oncology Center, Medical University of South Carolina, 171 Ashley Avenue, Charleston,
SC 29425, USA
} 


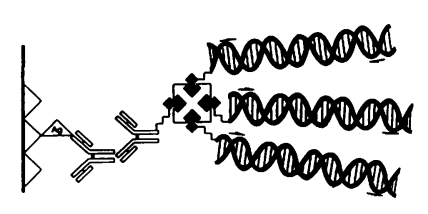

Figure 1. The principle of Universal Imuno-PCR. Antigen, specific primary antibody and biotinylated secondary antibody are stepwise immobilized as in routine ELISA assays. After that, free streptavidin and biotinylated signaling DNA are immobilized consecutively. The immobilized DNA molecules are then subject to a certain number of cycles of PCR amplification and visualized on agarose gel after ethidium bromide staining and destaining.

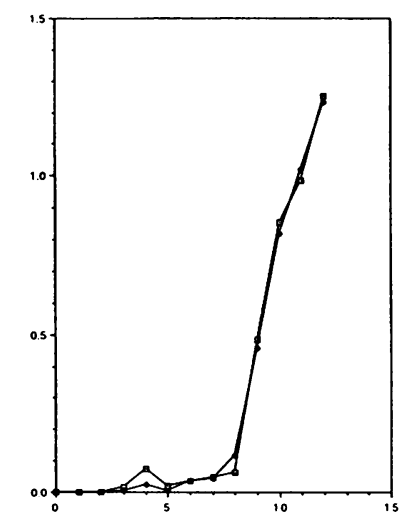

Figure 2. Detection of human proto-oncogene ETS1 immobilized in Immulon-4 wells by ELISA. The wells were coated overnight with serial tenfold $50 \mu$ l ETS1 dilutions at $4^{\circ} \mathrm{C}$. The working concentrations of the reagents were $1 \mathrm{ng} / \mu \mathrm{l}$ for ETS1-specific monoclonal antibody E44, 1:1000 for biotinylated sheep anti-mouse antibody and 1:3000 for streptavidin-alkaline phosphatase conjugate from Amersham. The signals were developed using $50 \mu 1.1 \mathrm{mg} / \mathrm{ml} \mathrm{p}$-Nitrophenyl phosphate disodium in $0.1 \mathrm{M}$ Tris $-\mathrm{Cl}, \mathrm{pH} 9.4$, containing $50 \mathrm{mM} \mathrm{MgCl}$ and determined with an ELISA plate reader. Y: $\mathrm{OD}_{405} ; \mathrm{X}: 12-0,10$-fold dilutions from $50 \mu \mathrm{g} / 50 \mu \mathrm{l}$ to $5 \mathrm{ag} / 50 \mu \mathrm{l}$; data from two parallel assays.

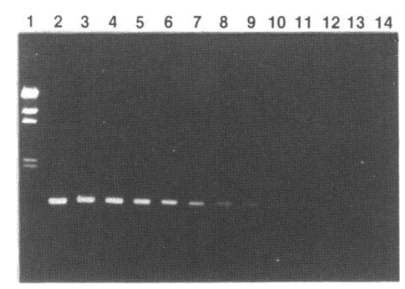

Figure 3. Detection of human proto-oncogene ETS1 immobilized in PCR tubes by an Immuno-PCR using commercial biotinylated secondary antibody and free streptavidin instead of the streptavidin - protein A chimera. The tubes were coated overnight as in the control ELISA. The working concentrations of ETS-specific mAb E44, biotinylated sheep anti-mouse antibody were the same as those used in the ETS1 ELISA assay. The working concentrations used in the following steps in Immuno-PCR were $1 \mathrm{ng} / \mu \mathrm{l}$ for free streptavidin and $3 \times 10^{-19} \mathrm{~mol} / \mu \mathrm{l}$ for biotinylated poTEL14 DNA fragments. PCR reactions were prepared as a master mixture with reagent molar concentrations and PCR profile as those in the recommended protocol (Perkin Elmer, GeneAmp). The signals were visualized on $1 \%$ agarose gel after ethidium bromide staining and destaining. Lane 1: Lambda HindIII digests; Lanes 2-12: $5 \mu \mathrm{l}$ PCR product from tubes coated with $50 \mu \mathrm{l}$ ETS1 tenfold serial dilutions at concentrations $1.92 \times 10^{-11} \mathrm{~mol} / \mu \mathrm{l}$ to $1.92 \times 10^{-23} \mathrm{~mol} / \mu \mathrm{l}$.

subsequent washing, $50 \mu \mathrm{l}$ biotinylated DNA tag in RDB at $3 \times 10^{-19} \mathrm{~mol} / \mu \mathrm{l}$ was added and incubated for one hour, followed by a final 5 times, three-minute TETBS washing. The immobilized DNA molecules in the tubes were then subjected to 30 cycles of PCR amplification in a volume of $50 \mu$ l GeneAmp (Perkin Elmer) batch reaction mixture prepared with a pair of p $\alpha$ TEL14-specific primers at hand (5'-ATACCTATTGCCTACGGCAG-3' and '5'-CGTTAGTAAATGAATTTTCTGT-3'). Each cycle was composed of three segments of $95^{\circ} \mathrm{C}$ for one minute, $55^{\circ} \mathrm{C}$ for 2 minutes and $72^{\circ} \mathrm{C}$ for 3 minutes for denaturing, annealing and polymerizing, respectively. The signals were finally visualized by assaying $5 \mu \mathrm{l}$ PCR product of each sample on $1 \%$ agarose gel and ethidium bromide staining and destaining. The result showed that this universal Immuno-PCR procedure could detect ETS1 at a concentration as low as $9.6 \times 10^{-21} \mathrm{~mol}$ in $50 \mu \mathrm{l}$ aqueous sample $\left(9.6 \times 10^{-15} \mathrm{M}\right.$, or $\sim 5.78 \times 10^{3}$ molecules) (Figure 2). This is $10^{5}$ folds more sensitive than the control ELISA assay and practically reached the real existing signals as most antigen molecules in each $\mathbf{5 0}$ $\mu l$ input aqueous sample were not expected to be immobilized during overnight incubation.

A similar approach which used avidin precomplexed with the biotinylated DNA was recently reported (8). As noted by Sano et al. (9), such simplification introduced the possibility of saturating the binding sites of avidin by biotinylated DNA molecules. Since the system was developed primarily to detect antigen molecules existing at extremely low concentrations, such blocking might generate variations in signal strength of final PCR products. Instead, use of free streptavidin or avidin would eliminate such a possibility. In addition, unlike the avidin, streptavidin does not have carbohydrate moieties and a high pI. The higher specificity therefore makes streptavidin to be a more favorable candidate for Immuno-PCR systems.

Towards the maturation of an ultrasensitive protein (or carbohydrate) epitope detection methodology for routine laboratory or clinic practice, the existing quantitative competitive PCR (QC-PCR) (10) will be a promising approach to improve the stability of current versions of Immuno-PCR, and approaches such as 'single primer PCR', which uses a template with identical flanking priming sequences, 'DNA-antibody direct conjugation' (9), and simple automation with compatible plasticwear will not only further simplify the operation but also reduce the cost and advance its applications, especially in early diagnosis. It can be further speculated that with the development of branched primers with multivalent free $3^{\prime}$ termini, we will be able to apply in situ Universal Immuno-PCR to study those epitopes differentially expressed during normal development or involved in early stages of tumorigenesis, or pathogenesis.

\section{ACKNOWLEDGEMENTS}

We wish to thank Dr Connie Fisher for recombinant ETS1 protein, Dr Guoqi Pei for primer syntheses, Dr Greg Winter for p $\alpha$ TEL14 clone (7), Mr Mrinal Chakrabarty for maintaining E44 hybridoma and Ms Vivian Y.Hua for valuable discussions. This work was supported by NCI, DHHS, under Contract No. N01-C0-74102 with PRI/DynCorp and NIH grant CP05667.

\section{REFERENCES}

1. Saiki,R.K., et al. )1985) Science 230, 1350.

2. Sano,T., et al. (1992) Science 258, 120-122.

3. Harlow,E. and Lane,D. (1988) Antibodies: A Laboratory Manual. Cold Spring Harbor Laboratories, pp. 616-619.

4. Bhat,N.K., et al. (1990) Proc. Natl. Acad. Sci. USA 87, 3723-3727.

5. Koizumi,S., et al. (1990) Oncogene 5, 675-681.

6. Gram,H., et al. (1992) Proc. Natl. Acad. Sci. USA (1992) 89, 3578.

7. Marks,J.D., et al. (1991) J. Mol. Biol. 222, 581-597.

8. Ruzika,V., Ma:rz,W., Russ,A. and Cross,W. (1993) Science 260, 698-699.

9. Sano,T., Smith,C.L. and Cantor,C.R. (1993) Science 260, 699.

10. Siebert,P.D. and Larrick,J. (1992) Nature 359, 557-558. 